\title{
Platelet indices in type 1 diabetes mellitus
}

\author{
Mehmet Inanir, Isa Sincer, Yilmaz Gunes \\ Department of Cardiology, Bolu Abant Izzet Baysal University, Faculty of Medicine, Bolu, Turkey
}

\section{ABSTRACT}

Aim: We aimed to compare platelet counts (Plt), plateletcrit (PCT) and platelet distribution width (PDW) values of type 1 diabetes mellitus (T1DM) patients with those of healthy subjects.

Methods: The records of 39 T1DM patients who were hospitalized between January 2016 and May 2018 were retrospectively analyzed. Control group consisted age and body mass index matched nondiabetic patients. Subjects having history of cardiovascular disease or any other systemic disease were excluded.

Results: Compared to control group Plt $\left(270 \pm 63\right.$ vs. $\left.215 \pm 35 \mathrm{k} / \mathrm{mm}^{3}\right)$, PCT $(0.217 \pm 0.057$ vs. $0.168 \pm 0.034 \%$ ) and PDW [17.4(16.2-20.4) vs. 17(12.5-19.4) \%] were significantly higher in T1DM patients.

Conclusion: Platelet indices which are common, simple and inexpensive hemogram parameters are increased T1DM patients.

Keywords: Type 1 diabetes mellitus, plateletcrit, inflammation, platelet counts, hematological indices.

Copyright (C) 2019 experimentalbiomedicalresearch.com

Corresponding Author: Dr. Mehmet Inanir

Department of Cardiology, Bolu Abant Izzet Baysal

University, Faculty of Medicine, Bolu, Turkey

E mail: mdmehmetinanir@yahoo.com

ORCID ID: https://orcid.org/0000-0003-1784-3584

Received 2019-02-01, Revised 2019-02-28

Accepted 2019-03-03

Publication Date 2019-03-14

\section{Introduction}

Diabetes is increasing in frequency day by day. Due to its complications it's a major health concern [1]. It's especially associated with increased risk of vascular disease. Inflammation has been claimed for long-term complications of diabetes [2-5]. Inflammation accelerates the development of atherosclerosis and may trigger atherosclerotic plaque rupture [6]. Platelets play an important role in inflammation, thrombosis and atherogenesis and may contribute to the development of vascular complications in subjects with diabetes [7]. Contrast to type 2 diabetes Type 1 diabetes mellitus (T1DM) develops at younger ages and T1DM is the most common form of diabetes in adolescents [8]. Therefore it may be important to predict possible long term complications by simple tests. Hemogram parameters have been suggested as novel 
inflammatory markers [9-11]. Recent studies proposed that abnormalities in platelets indices could be associated with an increased risk for developing vascular complications in Type 2 diabetes [12]. Platelet indices such as plateletcrit (PCT), platelet distribution width (PDW), and platelet count (Plt) have been investigated in the diagnosis, treatment and follow-up of various diseases [3, 13].

In the present study, we aimed to compare Plt, PCT and PDW values of Type 1 diabetes mellitus (T1DM) patients with those of healthy subjects.

\section{Methods}

Hospital records of 39 patients with T1DM who were followed in the endocrinology and metabolism diseases outpatient clinic of our hospital between 2016 January and May 2018 were retrospectively analyzed. Control group consisted age and body mass index matched nondiabetic patients. The study protocol was approved by Bolu Abant Izzet Baysal University Clinical Research Ethics Committee, Date: 20.12.2018. Decision number: 2018/260. All procedures performed in studies involving human participants were in accordance with the ethical standards of the institutional and/or national research committee and with the 1964 Helsinki declaration and its later amendments or comparable ethical standards.

T1DM was defined according to the American Diabetes Association criteria [14]. Age, gender, body mass index, hypertension and echocardiographic parameters such as ejection fraction (EF), left ventricular diastolic diameters (LVDD) and laboratory parameters, such as fasting plasma glucose, creatinine, white blood cell count (WBC), hemoglobin (Hb), hematocrit (Htc), mean corpuscular volume (MCV), red cell distribution width (RDW), Plt, mean platelet volume (MPV), were obtained from database and patient files of the institution.

Subjects having history of coronary artery disease, peripheral artery disease, heart failure, structural heart disease, chronic lung disease, liver or renal failure, thyroid disorders, malignancies, electrolyte imbalances or any other systemic disease were excluded.

Peripheral venous blood samples were drawn from patients who during regular follow-up checkups. Serum glucose, creatinine, total cholesterol, high-density lipoprotein cholesterol, triglyceride and low-density lipoprotein cholesterol were measured using an automatic biochemical analyzer (Architect C8000, USA). Complete blood count and platelet volumes were determined using simultaneous optical and impedance measurements (Cell Dyn 3700; Abbott Diagnostics, Lake Forest, Illinois, USA). Platelet, neutrophil, lymphocyte, monocytes, eosinophil, white blood cell (WBC), platelet distribution width (PDW), red cell distribution width (RDW), mean platelet volume (MPV) and PCT values of each patient were recorded.

\section{Statistical analysis}

Statistical analysis was conducted with SPSS software (SPSS 18.0 for Windows, IBM Co, Chicago, IL, USA). Distribution of the variables in study groups were analyzed by Kolmogorov-Smirnov test. Normal distributed variables were compared by $\mathrm{T}$ test and expressed as mean \pm standard deviation. Variables without normal distribution were compared with Mann Whitney $U$ test and expressed as median (IQR: interquartilerange). Chi-square test was used for comparison of nonparametric variables. A $p$ value lower than 0.05 was considered statistically significant. 


\section{Results}

Mean age, body mass index (BMI) and frequencies of sex, hypertension, smoking and hyperlipidemia were not significantly different between study patients and control group (Table 1). Compared to control group fasting plasma glucose (276 (116-535) vs. 96 (78-111) $\mathrm{mg} / \mathrm{dL}, p<0.001)$, triglyceride (104 (47-395) vs. $81(33-208) \mathrm{mg} / \mathrm{dL}, \quad p=0.040)$; total cholesterol 186 (108-305) vs. 160 (124-220) $\mathrm{mg} / \mathrm{dL}, p=0.007)$; PDW [17.4 (16.2-20.4) vs. $17(12.5-19.4) \%, p=0.043)$; neutrophil count (4.72 (2.28-6.75) vs. $3.65(2.29-5.55) \mathrm{u} / \mathrm{mm}^{3}$, $p=0.022)$; LVDD 4.5 (3.3-5.2) vs. 4.5 (4.2$5.1) \mathrm{cm}, p=0.033)$; Plt (270 \pm 63 vs. $215 \pm 35$ $\left.\mathrm{k} / \mathrm{mm}^{3}, p<0.001\right)$; WBC $(7.7 \pm 1.5$ vs. $6.4 \pm 1.2$ $\left.\mathrm{u} / \mathrm{mm}^{3}, \quad p=0.001\right)$; lymphocyte count $\left(2.40 \pm 0.50\right.$ vs. $\left.2.01 \pm 0.47 \mathrm{u} / \mathrm{mm}^{3}, p=0.001\right)$ and PCT $(0.217 \pm 0.057$ vs. $0.168 \pm 0.034 \%$, $p<0.001)$ were significantly higher in T1DM patients. There were no significant differences in creatinine, LDL-cholesterol and HDLcholesterol levels, hemoglobin, MPV, eosinophil and monocyte counts, RDW and LVEF between two groups (Table 2).

Table 1. General characteristics of the study groups.

\begin{tabular}{|l|l|l|l|}
\hline $\begin{array}{l}\text { Baseline } \\
\text { characteristics }\end{array}$ & $\begin{array}{l}\text { Control(n=39) } \\
\text { Median(Min-Max., } \\
\%)\end{array}$ & $\begin{array}{l}\text { DM(n=39) } \\
\text { Median(Min-Max., } \\
\%)\end{array}$ & $p$ \\
\hline Age (years) & $35(25-43)$ & $32(18-43)$ & 0.55 \\
\hline $\begin{array}{l}\text { Body mass index } \\
\text { (kg/m2) }\end{array}$ & $24(17-35)$ & $22(18-36)$ & 0.93 \\
\hline Male/female & $26 / 13$ & $23 / 16$ & 0.48 \\
\hline Hypertension (\%) & $3(8 \%)$ & $4(10 \%)$ & 0.47 \\
\hline Smoking & $8(25 \%)$ & $7(18 \%)$ & 0.77 \\
\hline Hyperlipidemia & $2(5 \%)$ & $3(8 \%)$ & 0.64 \\
\hline
\end{tabular}

\section{Discussion}

T1DM is an autoimmune disease process that develops through the interaction of genetic and environmental factors. It is characterized by progressive beta-cell destruction as a result of inflammation in the pancreas and total insulin deficiency as a result [15]. DM is a 'prothrombotic state' associated with atherosclerosis and inflammation. Tendency to thrombosis is increased in DM patients with increased platelet reactivity [16]. Hyperglycemia contributes to heightened platelet reactivity through glycation of platelet proteins. Besides, hypertriglyceridemia also increases platelet reactivity [17]. Insulin has also been shown to antagonize the effect of platelet agonists [18].

Chronic complications such as nephropathy, retinopathy, neuropathy microangiopathy and macroangiopathy are the most important problems of T1DM patients. The microvascular complications of diabetes are major causes of morbidity in diabetics and are generally detected quite late [3]. Early diagnosis of late complications of T1DM is very important in terms of prolongation and improvement of life [19-21]. Several studies have shown that platelet aggregation plays a role in the development of microvascular and macrovascular disease in DM patients [16].

Platelet activation plays central role in the pathogenesis of homeostasis and thrombosis [22]. Furthermore, platelets play important role in inflammatory process. Endothelial dysfunction and inflammation has been claimed for long-term complications of diabetes [2-5]. Inflammation accelerates the development of atherosclerosis. Platelets may play a role through both thrombogenic mechanisms, inflammatory pathways.

Plt has been found to be increased in cardiovascular diseases and vascular complications [23-25]. PDW and PCT are platelet parameters reflecting thrombotic activity [26]. PCT is a parameter of platelet 
Table 2. Comparison of laboratory data of the study groups.

\begin{tabular}{|c|c|c|c|}
\hline Parameters & Control $(n=39)$ & DM $(n=39)$ & $p$ \\
\hline Creatinine (mg/dL) & $0.81(0.66-0.90)$ & $0.80(0.44-1.32)$ & 117 \\
\hline Fasting plasma glucose (mg/dL) & $96(78-111)$ & $276(116-535)$ & $<0.001$ \\
\hline LDL-cholesterol(mg/dL) & $93(66-135)$ & $96(57-200)$ & 0.593 \\
\hline Triglyceride (mg/dL) & $81(33-208)$ & $104(47-395)$ & 0.040 \\
\hline Total cholesterol (mg/dL) & $160(124-220)$ & $186(108-305)$ & 0.007 \\
\hline Hemoglobin (gr/dL) & $14.2(10,4-18.2)$ & $13.7(11.0-16.3)$ & 0.054 \\
\hline PDW (\%) & $17(12.5-19.4)$ & $17.4(16.2-20.4)$ & 0.043 \\
\hline MPV (FI) & $7.7(6.1-10.5)$ & $7.5(5.8-12.3)$ & 0.849 \\
\hline Eosinophil, $\left(\mathbf{u} / \mathbf{m m}^{3}\right)$ & $0.14(0.00-0.77)$ & $0.14(0.04-0.57)$ & 0.745 \\
\hline Neutrophil, $\left(\mathbf{u} / \mathbf{m m}^{3}\right)$ & $3.65(2.29-5.55)$ & $4.72(2.28-6.75)$ & 0.022 \\
\hline Monocyte, $\left(\mathrm{u} / \mathrm{mm}^{3}\right)$ & $0.511(0.18-4.60)$ & $0.50(0.13-0.71$ & 0.292 \\
\hline EF(\%) & $65(57-65)$ & $64(57-75)$ & 0.371 \\
\hline $\operatorname{LVDD}(\mathbf{c m})$ & $4.5(4.2-5.1)$ & $4.5(3.3-5.2)$ & 0.033 \\
\hline HDL-cholesterol (mg/dL) & $46 \pm 8$ & $46 \pm 11$ & 0.870 \\
\hline Platelet counts (Plt) $\left(\mathrm{k} / \mathrm{mm}^{3}\right)$ & $215 \pm 35$ & $270 \pm 63$ & $<0.001$ \\
\hline $\mathbf{W B C},\left(\mathbf{u} / \mathbf{m m}^{3}\right)$ & $6.4 \pm 1.2$ & $7.7 \pm 1.5$ & 0.001 \\
\hline Lymphocyte & $2.01 \pm 0.47$ & $2.40 \pm 0.50$ & 0.001 \\
\hline RDW (\%) & $14.8 \pm 1.4$ & $15.3 \pm 1.2$ & 0.154 \\
\hline PCT & $0.168 \pm 0.034$ & $0.217 \pm 0.057$ & $<0.001$ \\
\hline
\end{tabular}

Values: Median (Min-Max.) and mean \pm SD. PDW: Platelet distribution width; RDW: Red cell distribution width; MPV: Mean platelet volume; HDL: high-density lipoprotein; LDL: low-density lipoprotein; WBC: White blood count; PCT: plateletcrit.

concentration and provides information on platelet production and activity [27]. It has been shown that there is a relationship between Plt and PCT reflecting the risk of platelet activation and potential thrombotic event [28].
Recent studies have suggested that PCT can provide more comprehensive and correct information about platelet activation [17, 29]. Some studies have shown that PCT has the potential to predict the risk of thrombosis. In 
some studies, PCT was found to be associated with coronary artery disease [23-25].

We thought that PCT values may give us more accurate results about the course of diabetic cardiovascular complications. PCT may be associated with thrombotic activity that predicts cardiovascular mortality and morbidity in T1DM.

\section{Conclusion}

Our findings suggest that Plt and PCT are increased in T1DM. When these results are verified by larger-scale studies, this may lead to modification of the treatment strategies based on follow-up these indices.

Informed Consent: Informed consent was obtained from all individual participants included in the study.

Conflicts of interest: There are no conflicts of interest.

Funding sources: This research did not receive any specific grant from funding agencies in the public, commercial, or not-forprofit sectors.

\section{References}

[1]Moţă̧̆̌ăianu A, Maier S, Bajko Z, Voidazan S, Bălaşa R, Stoian A. Cardiac autonomic neuropathy in type 1 and type 2 diabetes patients. BMC Neurol. 2018; 18(1):126.

[2]Balasubramaniam K, Viswanathan GN, Marshall SM, Zaman AG. Increased atherothrombotic burden in patients with diabetes mellitus and acute coronary syndrome: a review of antiplatelet therapy. Cardiol Res Pract. 2012; 2012:909154.

[3]Jindal S, Gupta S, Gupta R, Kakkar A, Singh HV, Gupta K, et al. Platelet indices in diabetes mellitus: indicators of diabetic microvascular complications. Hematology. 2011; 16(2):86-89.
[4]Hekimsoy Z, Payzin B, Örnek T, Kandoğan G. Mean platelet volume in Type 2 diabetic patients. J Diabetes Complications. 2004; 18(3):173-76.

[5]Wendland AE, Farias MG, Manfroi WC. Volume plaquetário médio e doença cardiovascular. J Bras Patol Med Lab. 2009; 45(5):371-78.

[6]Sabatine MS, Morrow DA, Cannon CP, Murphy SA, Demopoulos LA, DiBattiste $\mathrm{PM}$, et al. Relationship between baseline white blood cell count and degree of coronary artery disease and mortality in patients with acute coronary syndromes: a TACTICS-TIMI 18 (Treat Angina with Aggrastat and determine Cost of Therapy with an Invasive or Conservative StrategyThrombolysis in Myocardial Infarction 18 trial)substudy. J Am Coll Cardiol. 2002; 40(10):1761-68.

[7]Gawaz M, Langer H, May AE. Platelets in inflammation and atherogenesis. $\mathrm{J}$ Clin Invest. 2005; 115(12):3378-84.

[8]Dabelea D, Mayer-Davis EJ, Saydah S, Imperatore $\mathrm{G}$, Linder $\mathrm{B}$, Divers $\mathrm{J}$, et al. Prevalence of type 1 and type 2 diabetes among children and adolescents from 2001 to 2009. JAMA. 2014; 311(17):1778-86.

[9]Aktas G, Sit M, Dikbas O, Tekce B, Savli $\mathrm{H}$, Tekce H, et al. Could red cell distribution width be a marker in Hashimoto's thyroiditis? Exp Clin Endocrinol Diabetes. 2014; 122(10):572-74.

[10]Clarke K, Sagunarthy R, Kansal S. RDW as an additional marker in inflammatory bowel disease/undifferentiated colitis. Dig Dis Sci. 2008; 53(9):2521-23.

[11]Gasparyan AY, Stavropoulos-Kalinoglou A, Toms TE, Douglas KM, Kitas GD. Association of mean platelet volume with hypertension in rheumatoid arthritis. 
Inflamm Allergy Drug Targets. 2010; 9(1):45-50.

[12]Alhadas KR, Santos SN, Freitas MMS, Viana SMS, Ribeiro LC, Costa MB. Are platelet indices useful in the evaluation of type 2 diabetic patients? JBPML. 2016; 52(2):96-102.

[13] Sahin F, Yildiz P. Serum platelet, MPV, PCT and PDW values, neutrophil to lymphocyte and platelet to lymphocyte ratios in lung cancer diagnosis. Eur Respiratory Soc; 2015: PA4279.

[14] Association AD. 2. Classification and diagnosis of diabetes: standards of medical care in diabetes-2018. Diabetes care. 2018; 41(Supplement 1):S13-S27.

[15] Sperling MA, Tamboriane WV, Battelino T, Weinzimer SA, Phillip M. Diabetes Mellitus. In: Sperling MA, editor. Pediatric Endocrinology E-Book. Elsevier Health Sciences. 4th Edition. 2014; p. 846.

[16]Koltai K, Feher G, Kesmarky G, Keszthelyi Z, Czopf L, Toth K. The effect of blood glucose levels on hemorheological parameters, platelet activation and aggregation in oral glucose tolerance tests. Clin Hemorheol Microcirc. 2006; 35(4):517-25.

[17] Schneider DJ. Factors contributing to increased platelet reactivity in people with diabetes. Diabetes Care. 2009; 32(4):52527.

[18] Westerbacka J, Yki-Järvinen H, Turpeinen A, Rissanen A, Vehkavaara S, Syrjälä M, et al. Inhibition of platelet-collagen interaction: an in vivo action of insulin abolished by insulin resistance in obesity. Arterioscler Thromb Vasc Biol. 2002; 22(1):167-72.

[19] Svoren BM, Jospe N. Type 1 diabetes mellitus (immune mediated). In: Kleigman RM, Stanton BF, Schor NF, St Geme III
JW, Behrman RE, editors. Nelson textbook of Pediatrics. $20^{\text {th }}$ Ed. Philadelphia: Elsevier Inc. 2016; p. 2763-90.

[20]Rewers MJ, Pillay K, De Beaufort C, Craig ME, Hanas R, Acerini CL, et al. Assessment and monitoring of glycemic control in children and adolescents with diabetes. Pediatr Diabetes. 2014; 15(S20):102-14.

[21] Atkinson MA. Type 1 diabetes mellitus. In: Melmed S, Polonsky KS, Larsen PR, Kronenberg HM, editors. Williams textbook of endocrinology. $13^{\text {th }}$ Ed. Philadelphia: Elsevier Health Sciences. 2016. Chap 32.

[22]Li S, Zhu C-G, Guo Y-L, Xu R-X, Zhang $\mathrm{Y}$, Sun J, et al. The relationship between the plasma PCSK9 levels and platelet indices in patients with stable coronary artery disease. J Atheroscler Thromb. 2015; 22(1):76-84.

[23] Ravindran R, Krishnan LK. Increased platelet cholesterol and decreased percentage volume of platelets as a secondary risk factor for coronary artery disease. Pathophysiol Haemost Thromb. 2007; 36(1):45-51.

[24]Cetin MS, Cetin EHO, Akdi A, Aras D, Topaloglu S, Temizhan A, et al. Platelet distribution width and plateletcrit: novel biomarkers of ST elevation myocardial infarction in young patients. Kardiol Pol. 2017; 75(10):1005-12.

[25] Akpinar I, Sayin MR, Gursoy YC, Aktop Z, Karabag T, Kucuk E, et al. Plateletcrit and red cell distribution width are independent predictors of the slow coronary flow phenomenon. J Cardiol. 2014; 63(2):11218.

[26] Song YH, Park SH, Kim JE, Ahn JY, Seo YH, Park PH, et al. Evaluation of platelet indices for differential diagnosis of thrombocytosis by ADVIA 120. Korean J Lab Med. 2009; 29(6):505-9. 
[27] Subramaniam N, Mundkur S, Kini P, Bhaskaranand N, Aroor S. Clinico hematological study of thrombocytosis in children. ISRN Hematol. 2014; 29:2014: 389257.

[28]Uğur M, Ayhan E, Bozbay M, Çiçek G, Ergelen $\mathrm{M}$, Işık $\mathrm{T}$, et al. The independent association of plateletcrit with long-term outcomes in patients undergoing primary percutaneous coronary intervention. J Crit Care. 2014; 29(6):978-81.

[29] Li N, Hu H, Lindqvist M, WikströmJonsson E, Goodall AH, Hjemdahl P. Platelet-leukocyte cross talk in whole blood. Arterioscler Thromb Vasc Biol. 2000; 20(12):2702-8.

[30]Mutlu H, Artış TA, Erden A, Akca Z. Alteration in mean platelet volume and platicrit values in patients with cancer that developed thrombosis. Clin Appl Thromb Hemost. 2013; 19(3):331-33. 